\title{
Age- and sex-specific Canadian utility norms, based on the 2013-2014 Canadian Community Health Survey
}

\author{
Jason R. Guertin PhD, David Feeny PhD, Jean-Eric Tarride PhD
}

Cite as: CMAJ 2018 February 12;190:E155-61. doi: 10.1503/cmaj.170317

\begin{abstract}
BACKGROUND: Although many Canadian studies have provided disease-specific or patient group-specific utility scores, the utility score norms currently available for the general Canadian population are outdated. Canadian guideline recommendations for the economic evaluation of health technologies advocate for utilities reflecting those of the general population and for stratified analyses when results are heterogeneous; as such, there is also a need for age-, sex- and jurisdiction-specific utility score norms.
\end{abstract}

METHODS: We used data from the 20132014 Canadian Community Health Survey. We used the Health Utilities Index
Mark 3 to calculate utility scores. We estimated means (with 95\% confidence intervals [Cls]) and medians (with interquartile ranges [IQRs]) for utility scores. In addition to Canadian-level measures, we stratified all utility score norms by respondents' age, sex, and province or territory of residence. We weighted respondents' answers and computed 95\% Cls using sampling weights and bootstrap weights provided by Statistics Canada to extrapolate the study findings to the Canadian population.

RESULTS: Respondents to the 20132014 Canadian Community Health Survey represented 30014589 community- dwelling Canadians 12 years of age and older ( $98 \%$ of the Canadian population); half of the respondents were female (50.6\%), and the weighted average age was 44.8 (95\% Cl 44.7-44.9) years. The mean and median self-reported utility scores for Canadians were estimated at 0.863 (95\% Cl 0.861-0.865) and 0.927 (IQR 0.838-0.972), respectively.

INTERPRETATION: This study provides utility score norms for several age-, sexand jurisdiction-specific strata in Canada. These results will be useful for future cost-utility analyses and could serve as benchmark values for comparisons with future studies.
$\mathbf{U}$ se of economic evaluations is now common practice in the reimbursement of novel health technologies in Canada. Although several types of economic evaluations can be conducted, cost-utility analyses have been favoured in Canada and abroad, ${ }^{1-4}$ especially when examining interventions that can affect patients' health-related quality of life. The results of cost-utility analyses are generally presented in terms of the incremental cost per quality-adjusted life-year gained. The total number of quality-adjusted life-years gained by an individual assigned to a given treatment is obtained by multiplying the amount of time the individual remains in a given health state by a weighting function, the utility score, that reflects the preference value placed by the individual on the given state. By convention, "dead" is assigned a utility score of 0.00 , whereas "perfect health" is assigned of utility score of $1.00 .{ }^{5}$

In past years, there has been increasing interest in estimating utility score norms for the general population because these norms are of particular value when comparing specific patient subgroups with the general population and as inputs when accounting for gains in terms of health-related life expectancies within economic evaluations. Such norms are also of clinical value because they highlight how a given subset of patients may differ from the general population. Although population-level norms for the United States and the United Kingdom have been produced, ${ }^{6,7}$ Canadian data have mainly focused on subsamples of the country's population. In addition, these Canadian values, some of which were generated more than 15 years ago, are outdated and may not accurately reflect the general population today. ${ }^{8-16}$ Current Canadian guideline recommendations are encouraging health outcomes researchers to use estimates reflective of the general Canadian population. ${ }^{2}$ Furthermore, given that these recommendations also advocate for the production of stratified economic evaluations when results are heterogeneous, ${ }^{1,2}$ there is a clear need for much finer granularity in 
utility score inputs than what is currently available to produce age- or sex-stratified analyses at the provincial or territorial level.

One way of obtaining Canadian and stratum-specific utility score norms is to examine the utility score measures obtained through use of a generic, multi-attribute health status classification system administered to a representative sample of the current Canadian population. One such system, the Health Utilities Index Mark 3 (generally referred to as the HUI3), ${ }^{17-19}$ has been administered to representative samples of the communitydwelling Canadian population within multiple versions of the Canadian Community Health Survey since its inception in 2002. ${ }^{20}$ However, utility score norms based on these data have yet to be produced. Therefore, using the most recently released Canadian Community Health Survey data, we aimed to produce age- and sex-specific Canadian, provincial and territorial utility score norms, which can be used to conduct Canadian economic evaluations, monitor the health-related quality of life of the Canadian population and interpret utility scores generated in various studies. Furthermore, because the Canadian Community Health Survey also examines respondents' self-rated health, a metric that has been shown to predict morbidity and mortality, ${ }^{17}$ we also aimed to determine Canadian utility score norms corresponding to respondents' self-rated health.

\section{Methods}

\section{Survey design}

For this study, we used 2-year combined data from the 20132014 Canadian Community Health Survey. A detailed description of this survey can be found elsewhere. ${ }^{18}$ Briefly, Statistics Canada selects a representative sample of the Canadian population living in the 10 provinces and 3 territories aged 12 years or older to whom the questionnaire is to be administered. Individuals living on Indian Reserves and on Crown lands, Canadian residents of institutions, full-time members of the Canadian Forces and residents of certain remote regions are excluded. Statistics Canada estimates that the Canadian Community Health Survey covers about $98 \%$ of the Canadian population. ${ }^{19}$ Interviews were conducted in person using computer-assisted personal interviewing or by phone using computer-assisted telephone interviewing. ${ }^{19}$

\section{Health Utilities Index Mark 3}

Respondents' utility scores were assessed using the HUI3 instrument of the HUI system..$^{20-22}$ The HUI3 combines a generic comprehensive health status classification system and a generic health-related quality-of-life utility scoring system. It examines 8 health attributes (i.e., vision, hearing, speech, ambulation, dexterity, emotion, cognition and pain/discomfort), with each attribute having 5 or 6 levels; the combination of the various attributes and their levels creates 972000 unique health states. Utility scores for the HUI3 range from -0.36 to 1.00 , with "perfect health" having a utility score of 1.00 , "dead" having a utility score of 0.00 and "states worse than death" having utility scores less than 0.00 . The minimum clinically important difference for the HUI3 has been estimated at $0.03 .{ }^{22,23}$ In popula- tion health applications, some analysts use a minimum clinically important difference of $0.01 .{ }^{23}$ Similar to respondents' self-rated health, ${ }^{17}$ HUI3 scores have also been shown to be predictive of mortality and morbidity. ${ }^{24}$ In addition to providing utility scores reflective of Canadian community health preferences, ${ }^{21}$ it was the sole utility score instrument administered to respondents of the 2013-2014 Canadian Community Health Survey. ${ }^{25,26}$

\section{Self-rated health}

Respondents' self-rated health was examined using an ordered categorical scale (i.e., excellent, very good, good, fair or poor)..$^{25,26}$

\section{Statistical analysis}

We used descriptive statistics to summarize the sociodemographic characteristics of respondents. We examined results at the national level, with further stratification by the province or territory in which respondents resided. To preserve confidentiality, respondents from the Yukon, Northwest Territories and Nunavut were grouped, whereas respondents from all other provinces were analyzed separately. We presented descriptive statistics as absolute and relative frequencies, with the exception of respondents' age at the time of answering the survey, which we presented as the average age (with 95\% confidence interval [Cl]) within the Canadian and provincial or territorial populations and as the absolute and relative frequencies of mutually exclusive age categories.

For a small proportion of individuals, we could not estimate utility scores because they refused to answer key HUI3 questions; HUI3 data for these individuals were classified as missing, and they were excluded from the analysis. We used a multivariable logistic regression model that included all examined sociodemographic characteristics to identify predictors of nonresponse. We estimated utility scores from variables derived by Statistics Canada for those who completed the 30 HUI3 questions. In addition to the population-level norms, all utility scores were stratified by age (by 5-year increment), sex and jurisdiction (with our stratification approach creating 575 distinct strata). We then examined mean $(95 \% \mathrm{Cl}$ ) and median (interquartile range [IQR]) utility scores for all of the examined strata. In addition, we crosstabulated utility scores and respondents' self-rated health (excellent, very good, good, fair, poor).

We weighted all descriptive statistics to comply with Statistics Canada vetting rules; the sampling weights and bootstrapped weights used to estimate bootstrapped $95 \%$ Cls were provided by Statistics Canada and were used to extrapolate the results to the Canadian population covered by the Canadian Community Health Survey. We conducted all analyses with SAS version 9.3 software (SAS Institute Inc.), using survey-specific procedures (e.g., PROC SURVEYMEANS) when appropriate.

\section{Ethics approval}

We accessed the data through approved research data centres at McMaster University and Université Laval, following approval of the proposed research by Statistics Canada. All data were deidentified, and vetting procedures were applied to ensure confidentiality and protection of the respondents. 
Table 1 (part 1 of 2): Sociodemographic characteristics of the Canadian population*

\begin{tabular}{|c|c|c|}
\hline \multirow[b]{2}{*}{ Variable } & \multicolumn{2}{|c|}{ Weighted frequency $†$} \\
\hline & Absolute & $\begin{array}{l}\text { Relative, \% } \\
(95 \% \mathrm{CI})\end{array}$ \\
\hline Overall & 30014589 & 100 \\
\hline \multicolumn{3}{|l|}{ Sex } \\
\hline Male & 14815015 & $49.4(49.4-49.4)$ \\
\hline Female & 15199574 & $50.6(50.6-50.6)$ \\
\hline Age, yr, mean $(95 \% \mathrm{Cl})$ & \multicolumn{2}{|c|}{$44.8(44.7-44.9)$} \\
\hline \multicolumn{3}{|l|}{ Age group, yr } \\
\hline $12-19$ & 3180697 & $10.6(10.6-10.6)$ \\
\hline $20-24$ & 2419203 & $8.1(7.8-8.3)$ \\
\hline $25-29$ & 2373260 & $7.9(7.7-8.1)$ \\
\hline $30-34$ & 2321576 & $7.7(7.4-8.0)$ \\
\hline $35-39$ & 2296321 & $7.7(7.4-7.9)$ \\
\hline $40-44$ & 2415306 & $8.0(7.8-8.3)$ \\
\hline $45-49$ & 2334694 & $7.8(7.4-8.2)$ \\
\hline $50-54$ & 2708861 & $9.0(8.7-9.4)$ \\
\hline $55-59$ & 2576617 & $8.6(8.3-8.9)$ \\
\hline $60-64$ & 2184281 & $7.3(6.9-7.6)$ \\
\hline $65-69$ & 1822033 & $6.1(5.9-6.2)$ \\
\hline $70-74$ & 1301405 & $4.3(4.2-4.5)$ \\
\hline $75-79$ & 946319 & $3.2(3.0-3.3)$ \\
\hline $80-84$ & 656358 & $2.2(2.1-2.3)$ \\
\hline$\geq 85$ & 477658 & $1.6(1.5-1.7)$ \\
\hline \multicolumn{3}{|l|}{ Province or territory } \\
\hline British Columbia & 3978590 & $13.3(13.3-13.3)$ \\
\hline Alberta & 3358681 & $11.2(11.2-11.2)$ \\
\hline Saskatchewan & 875543 & $2.9(2.9-2.9)$ \\
\hline Manitoba & 1018598 & $3.4(3.4-3.4)$ \\
\hline Ontario & 11682112 & $38.9(38.9-38.9)$ \\
\hline Quebec & 6976483 & $23.2(23.2-23.2)$ \\
\hline New Brunswick & 643833 & $2.1(2.1-2.1)$ \\
\hline Nova Scotia & 810032 & $2.7(2.7-2.7)$ \\
\hline Prince Edward Island & 125591 & $0.4(0.4-0.4)$ \\
\hline $\begin{array}{l}\text { Newfoundland and } \\
\text { Labrator }\end{array}$ & 452485 & $1.5(1.5-1.5)$ \\
\hline Yukon & 31174 & $0.1(0.1-0.1)$ \\
\hline Northwest Territories & 35230 & $0.1(0.1-0.1)$ \\
\hline Nunavut & 26237 & $0.1(0.1-0.1)$ \\
\hline \multicolumn{3}{|l|}{ Residence, urban v. rural } \\
\hline Population centre & 24564540 & $81.8(81.4-82.3)$ \\
\hline Rural & 5450048 & $18.2(17.7-18.6)$ \\
\hline
\end{tabular}

\section{Results}

Sociodemographic characteristics of weighted sample For the 2013-2014 Canadian Community Health Survey, 147009 households agreed to participate in the survey, and 128310 individuals responded (response rate of $87.3 \%$ ). These respondents were weighted to represent a weighted sample of 30014589 Canadians (about $98 \%$ of the Canadian population). Table 1 provides the sociodemographic characteristics of these respondents, and Appendix 1 (available at www.cmaj.ca/lookup/suppl/doi:10.1503/ cmaj.170317/-/DC1) provides the sociodemographic characteristics for each of the stratified jurisdictions. Just over half of the weighted sample were female (weighted frequency count 15199574 [50.6\%]), and the average age in the weighted sample was estimated at 44.8

\section{Table 1 (part 2 of 2): Sociodemographic characteristics of} the Canadian population*

\begin{tabular}{|c|c|c|}
\hline \multirow[b]{2}{*}{ Variable } & \multicolumn{2}{|c|}{ Weighted frequency $†$} \\
\hline & Absolute & $\begin{array}{l}\text { Relative, \% } \\
\text { (95\% CI) }\end{array}$ \\
\hline \multicolumn{3}{|l|}{ Marital status } \\
\hline Single & 8987047 & $29.9(29.5-30.4)$ \\
\hline Married or common-law & 17277751 & $57.6(57.0-58.1)$ \\
\hline Separated or divorced & 2331041 & $7.8(7.5-8.0)$ \\
\hline Widowed & 1347772 & $4.5(4.4-4.6)$ \\
\hline $\begin{array}{l}\text { Don't know, refusal, not } \\
\text { stated }\end{array}$ & 70977 & $0.2(0.2-0.3)$ \\
\hline \multicolumn{3}{|l|}{ Education } \\
\hline $\begin{array}{l}\text { Less than secondary } \\
\text { school graduation }\end{array}$ & 5805957 & $19.3(19.0-19.7)$ \\
\hline $\begin{array}{l}\text { Secondary school } \\
\text { graduation }\end{array}$ & 5732456 & $19.1(18.7-19.5)$ \\
\hline Some postsecondary & 1634752 & $5.4(5.2-5.7)$ \\
\hline Postsecondary graduation & 16363236 & $54.5(54.0-55.0)$ \\
\hline Not stated & 478188 & $1.6(1.5-1.7)$ \\
\hline \multicolumn{3}{|l|}{ Gross household income, \$ } \\
\hline$<30000$ & 4896777 & $16.3(15.9-16.7)$ \\
\hline $30000-59999$ & 7897030 & $26.3(25.9-26.8)$ \\
\hline $60000-89999$ & 6315970 & $21.0(20.6-21.4)$ \\
\hline$>90000$ & 10904813 & $36.3(35.8-36.9)$ \\
\hline \multicolumn{3}{|l|}{ Self-rated health } \\
\hline Excellent & 6206931 & $20.7(20.3-21.1)$ \\
\hline Very good & 11550461 & $38.5(38.1-39.0)$ \\
\hline Good & 8840601 & $29.5(29.0-29.9)$ \\
\hline Fair & 2530063 & $8.4(8.2-8.7)$ \\
\hline Poor & 854075 & $2.8(2.7-3.0)$ \\
\hline
\end{tabular}

Note: $\mathrm{Cl}=$ confidence interval.

*A total of 128310 Canadian respondents answered the questionnaire.

†Except where indicated otherwise. 
(95\% Cl 44.7-44.9) years. More than half of the weighted sample rated their health as either excellent (weighted frequency count 6206931 [20.7\%]) or very good (weighted frequency count 11550461 [38.5\%]).

\section{Health Utilities Index Mark 3}

Of the 128310 respondents to the 2013-2014 Canadian Community Health Survey, 4656 (3.6\%) did not provide full responses to the HUI3 questions, which prevented us from esti-

Table 2: Predictors of nonresponse to the Health Utilities Index Mark 3 questions within the 2013-2014 Canadian Community Health Survey

\begin{tabular}{|c|c|}
\hline Variable & OR $(95 \% \mathrm{Cl})$ \\
\hline Sex, female & $0.872(0.819-0.928)$ \\
\hline Age, per year & $1.037(1.034-1.039)$ \\
\hline \multicolumn{2}{|l|}{ Marital status } \\
\hline Married or common-law & 1.000 (ref) \\
\hline Single & $1.310(1.192-1.440)$ \\
\hline Separated or divorced & $1.030(0.931-1.139)$ \\
\hline Widowed & $0.998(0.913-1.090)$ \\
\hline Don't know, refusal, not stated & $1.545(0.909-2.627)$ \\
\hline \multicolumn{2}{|l|}{ Education } \\
\hline Less than secondary school graduation & 1.000 (ref) \\
\hline Secondary school graduation & $0.789(0.723-0.861)$ \\
\hline Some postsecondary education & $0.871(0.741-1.023)$ \\
\hline Postsecondary graduation & $0.686(0.637-0.739)$ \\
\hline Not stated & $1.714(1.446-2.032)$ \\
\hline \multicolumn{2}{|l|}{ Gross household income, \$ } \\
\hline$<30000$ & 1.000 (ref) \\
\hline $30000-59999$ & $0.809(0.750-0.873)$ \\
\hline $60000-89999$ & $0.706(0.639-0.780)$ \\
\hline$\geq 90000$ & $0.573(0.515-0.637)$ \\
\hline \multicolumn{2}{|l|}{ Province or territory of residence } \\
\hline Ontario & 1.000 (ref) \\
\hline British Columbia & $1.116(1.011-1.232)$ \\
\hline Alberta & $1.479(1.333-1.642)$ \\
\hline Saskatchewan & $1.478(1.313-1.663)$ \\
\hline Manitoba & $1.616(1.442-1.812)$ \\
\hline Quebec & $0.594(0.536-0.658)$ \\
\hline New Brunswick & $1.011(0.864-1.184)$ \\
\hline Nova Scotia & $1.141(0.986-1.321)$ \\
\hline Prince Edward Island & $1.121(0.890-1.412)$ \\
\hline Newfoundland and Labrador & $1.277(1.084-1.505)$ \\
\hline Yukon, Northwest Territories, Nunavut & $1.237(0.996-1.535)$ \\
\hline Residing in a population centre & $0.988(0.924-1.057)$ \\
\hline
\end{tabular}

mating their utility scores. Results of a multivariable regression model comparing these individuals with those who provided complete responses to the HUI3 questions are shown in Table 2. According to this model, respondents who were women, who were more educated, who had a higher household income and who resided in the province of Quebec were more likely to answer all of the HUI3 questions. By contrast, respondents who were older, who were single and who resided in Alberta, British Columbia, Manitoba, Newfoundland and Labrador, or Saskatchewan were more likely not to answer all of the HUI3 questions.

A histogram of the utility score distribution for the remaining 123654 respondents (96.4\%) is presented in Figure 1. As expected, the distribution was not normal. The upper bound for utility scores was 1.00 , and the lower bound, involving a small proportion of the sample, was less than zero.

Table 3 provides the age- and sex-stratified utility scores for the Canadian population; jurisdiction-stratified tables are provided in Appendix 2 (available at www.cmaj.ca/lookup/suppl/doi:10.1503/ cmaj.170317/-/DC1). The mean and median utility scores for all Canadians within the 2013-2014 period were estimated at 0.863 (95\% Cl 0.861-0.865) and 0.927 (IQR 0.838-0.972), respectively.

Cross-tabulation of utility score measures with respondents' selfrated health was possible for the majority of respondents for whom utility scores were provided (weighted frequency count 29313389 [99.9\%]). Average and median utility scores for each of the 5 levels of self-reported health are shown in Table 4. As expected, utility scores decreased with worsening self-rated health, from a high of 0.942 $(95 \% \mathrm{Cl} 0.940-0.944)$ for respondents who reported that their health was "excellent" to a low of $0.399(95 \% \mathrm{Cl} 0.378-0.421)$ for respondents who reported that their health was "poor."

\section{Interpretation}

We estimated that the average utility score for the 2013-2014 Canadian population was 0.863 (95\% Cl $0.861-0.865)$. Slight variations in the average utility score were observed among the

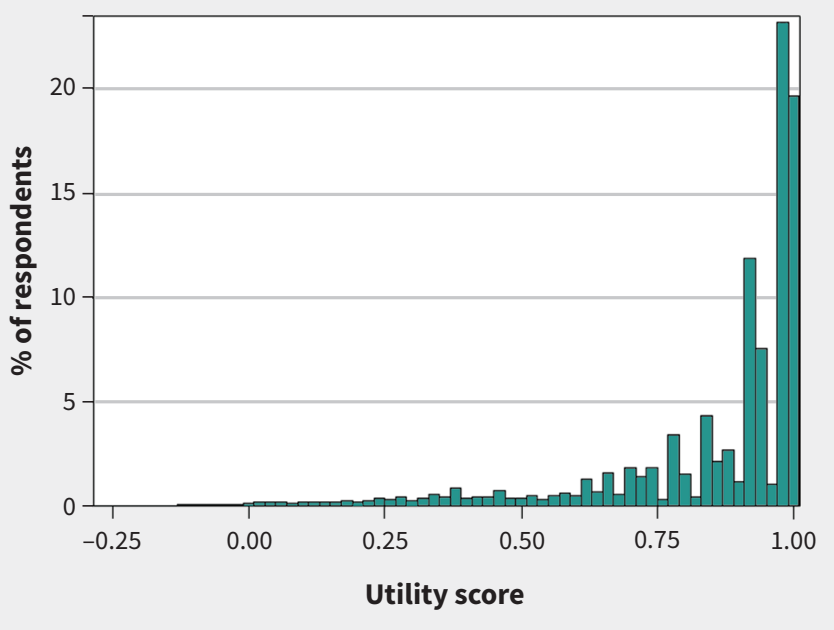

Figure 1: Utility score distribution among respondents to the 2013-2014 Canadian Community Health Survey. The histogram has been truncated to comply with Statistics Canada's vetting rules. 
various provinces and territories. All provincial and territorial averages were within the threshold for the minimum clinically important difference, showing that results differed only slightly among provinces.

Table 3 (part 1 of 2): Age- and sex-stratified utility norms of the Canadian population*

\section{Utility score norm}

\begin{tabular}{|c|c|c|}
\hline Variable & Mean $(95 \% \mathrm{CI})$ & Median (IQR) \\
\hline Males & \multicolumn{2}{|c|}{ Weighted frequency = 14486976} \\
\hline \multicolumn{3}{|c|}{ Age group, yr } \\
\hline $12-19$ & $0.892(0.886-0.897)$ & $0.927(0.864-0.981)$ \\
\hline $20-24$ & $0.892(0.883-0.900)$ & $0.928(0.866-0.981)$ \\
\hline $25-29$ & $0.902(0.894-0.911)$ & $0.947(0.888-0.983)$ \\
\hline $30-34$ & $0.899(0.888-0.909)$ & $0.943(0.883-0.983)$ \\
\hline 35-39 & $0.898(0.889-0.908)$ & $0.950(0.879-0.983)$ \\
\hline $40-44$ & $0.901(0.892-0.909)$ & $0.948(0.904-0.981)$ \\
\hline $45-49$ & $0.873(0.862-0.885)$ & $0.930(0.859-0.971)$ \\
\hline $50-54$ & $0.856(0.841-0.870)$ & $0.925(0.846-0.965)$ \\
\hline $55-59$ & $0.850(0.840-0.860)$ & $0.929(0.833-0.964)$ \\
\hline $60-64$ & $0.842(0.833-0.852)$ & $0.919(0.828-0.962)$ \\
\hline $65-69$ & $0.848(0.839-0.856)$ & $0.919(0.814-0.961)$ \\
\hline $70-74$ & $0.841(0.829-0.852)$ & $0.906(0.800-0.961)$ \\
\hline $75-79$ & $0.809(0.794-0.823)$ & $0.904(0.726-0.958)$ \\
\hline $80-84$ & $0.748(0.727-0.768)$ & $0.848(0.648-0.950)$ \\
\hline$\geq 85$ & $0.682(0.655-0.708)$ & $0.777(0.540-0.905)$ \\
\hline All ages & $0.871(0.868-0.874)$ & $0.928(0.849-0.974)$ \\
\hline
\end{tabular}

Age group, $y r$

\begin{tabular}{lll}
$12-19$ & $0.879(0.873-0.886)$ & $0.927(0.827-0.980)$ \\
$20-24$ & $0.890(0.880-0.899)$ & $0.931(0.865-0.977)$ \\
$25-29$ & $0.902(0.895-0.910)$ & $0.948(0.891-0.980)$ \\
\hline $30-34$ & $0.893(0.884-0.903)$ & $0.948(0.872-0.981)$ \\
\hline $35-39$ & $0.890(0.882-0.898)$ & $0.943(0.866-0.981)$ \\
\hline $40-44$ & $0.874(0.862-0.886)$ & $0.946(0.861-0.977)$ \\
\hline $45-49$ & $0.862(0.851-0.873)$ & $0.923(0.837-0.966)$ \\
\hline $50-54$ & $0.842(0.830-0.854)$ & $0.919(0.830-0.963)$ \\
\hline $55-59$ & $0.830(0.821-0.840)$ & $0.905(0.777-0.959)$ \\
\hline $60-64$ & $0.841(0.833-0.849)$ & $0.915(0.792-0.961)$ \\
\hline $65-69$ & $0.837(0.829-0.845)$ & $0.907(0.778-0.960)$ \\
$70-74$ & $0.831(0.821-0.840)$ & $0.905(0.778-0.959)$ \\
\hline $75-79$ & $0.778(0.764-0.792)$ & $0.904(0.668-0.954)$ \\
\hline $80-84$ & $0.736(0.719-0.754)$ & $0.853(0.612-0.951)$ \\
$\geq 85$ & $0.616(0.592-0.641)$ & $0.688(0.375-0.905)$ \\
All ages & $0.856(0.853-0.859)$ & $0.926(0.829-0.969)$ \\
\hline
\end{tabular}

We also provided reference utility scores for individuals, which can be used when researchers have collected only respondents' self-rated health. Similar to what had been shown by others, ${ }^{27}$ our results highlight that any variation in self-reported health was associated with a utility score difference extending beyond the minimum clinically important difference. Such results emphasize the importance for researchers, clinicians and decision-makers of recognizing the value of changes in an individual's self-rated health.

Our study updates and extends out-of-date age- and sexspecific utility score norms at the Canadian, provincial and territorial levels using a representative sample of the current Canadian population. In 1999, using data from the 1994 National Population Health Survey, ${ }^{28}$ Mittmann and colleagues ${ }^{8}$ published Canadian utility norms for individuals as a function of the number (i.e., ranging from none to 11) and type of chronic diseases they reported experiencing. The average score for individuals with no chronic diseases (i.e., 0.93) has been recently cited by others as the Canadian HUI3 norm. ${ }^{29}$ Another set of estimates was reported by Kopec and colleagues, ${ }^{30}$ who used the same 1994 National Population Health Survey data to estimate that the average utility norms for Canadian men and women were 0.906 and 0.887 , respectively. Although our sex-specific estimates for the Canadian population are closer to those reported

Table 3 (part 2 of 2): Age- and sex-stratified utility norms of the Canadian population*

\section{Utility score norm}

\begin{tabular}{|lcc}
\hline Variable & Mean $(95 \% \mathrm{Cl})$ & Median (IQR) \\
\hline $\begin{array}{l}\text { Total population } \\
\text { Age group, } y r\end{array}$ & Weighted frequency $=29337370$ \\
\hline $12-19$ & $0.886(0.881-0.890)$ & $0.927(0.842-0.980)$ \\
\hline $20-24$ & $0.891(0.884-0.897)$ & $0.929(0.866-0.979)$ \\
\hline $25-29$ & $0.902(0.897-0.908)$ & $0.948(0.890-0.981)$ \\
\hline $30-34$ & $0.896(0.889-0.903)$ & $0.946(0.879-0.982)$ \\
\hline $35-39$ & $0.894(0.888-0.900)$ & $0.947(0.870-0.982)$ \\
\hline $40-44$ & $0.887(0.880-0.895)$ & $0.947(0.866-0.979)$ \\
\hline $45-49$ & $0.868(0.860-0.876)$ & $0.927(0.842-0.968)$ \\
\hline $50-54$ & $0.849(0.840-0.858)$ & $0.923(0.835-0.964)$ \\
\hline $55-59$ & $0.840(0.833-0.847)$ & $0.919(0.791-0.962)$ \\
\hline $60-64$ & $0.842(0.836-0.848)$ & $0.919(0.803-0.962)$ \\
\hline $65-69$ & $0.842(0.836-0.848)$ & $0.918(0.792-0.961)$ \\
\hline $70-74$ & $0.835(0.828-0.842)$ & $0.905(0.782-0.960)$ \\
\hline $75-79$ & $0.792(0.782-0.803)$ & $0.904(0.698-0.956)$ \\
\hline $80-84$ & $0.741(0.728-0.755)$ & $0.853(0.623-0.950)$ \\
\hline$\geq 85$ & $0.640(0.621-0.658)$ & $0.727(0.419-0.905)$ \\
\hline All ages & $0.863(0.861-0.865)$ & $0.927(0.838-0.972)$ \\
\hline
\end{tabular}

Note: $\mathrm{Cl}=$ confidence interval, IQR = interquartile range. *Utility scores were estimated for 123654 respondents. 
Table 4: Utility norms for the Canadian population in relation to self-rated health*

\begin{tabular}{llc} 
Self-rated & \multicolumn{2}{c}{ Utility score norm } \\
health & Mean $(95 \% \mathrm{CI})$ & Median (IQR) \\
\hline Excellent & $0.942(0.940-0.944)$ & $0.962(0.922-0.982)$ \\
\hline Very good & $0.910(0.908-0.912)$ & $0.947(0.904-0.975)$ \\
\hline Good & $0.842(0.839-0.846)$ & $0.905(0.777-0.960)$ \\
\hline Fair & $0.664(0.654-0.673)$ & $0.743(0.446-0.905$ \\
\hline Poor & $0.399(0.378-0.421)$ & $0.344(0.116-0.700)$ \\
\hline $\begin{array}{l}\text { Note: } \mathrm{Cl}=\text { confidence interval, IQR = interquartile range. } \\
\text { *Utility scores were estimated for 123 654 respondents. The weighted frequency of } \\
\text { responses was 29 313 389. }\end{array}$
\end{tabular}

by Kopec and colleagues ${ }^{30}$ than to those reported by Mittmann and colleagues, ${ }^{8}$ differences with our estimates remain greater than the minimum clinically important difference for HUI3. Although these differences could highlight a potential for utility norms to vary over time, the lack of a minimum clinically important difference between our estimates and those reported by Pohar and Jones (i.e., 0.87$)^{12}$ does not support this hypothesis. Future work is needed to examine whether Canadian utility score norms vary over time.

\section{Limitations}

Our work does have limitations. We could not estimate utility scores for a small proportion of respondents (4656 [3.6\%]). The health-related quality of life of nonrespondents may differ from that of respondents. As such, the norms we present may be biased by nonresponse. Furthermore, specific subgroups of Canadians are not covered by the Canadian Community Health Survey (i.e., individuals on Indian Reserves and on Crown Lands, those who are residents of institutions, full-time members of the Canadian Forces and residents of certain remote regions). Although we cannot assume that our estimates extend to these excluded subgroups, the exclusions represent only about $2 \%$ of the Canadian population aged 12 years or older. ${ }^{19}$

The utility scores that we present were estimated using the HUI3 scoring algorithm. Although the HUI3 is one of the most commonly used generic utility instruments and is recommended for economic evaluations by Canadian guidelines, ${ }^{1,2,31-33}$ other instruments can be used (e.g., EuroQOL-5 Dimensions, ${ }^{34}$ Short Form 6-Dimensions health status classification system ${ }^{35}$ ). Previous work has shown that using different approaches to assess individuals' utility scores and using different scoring algorithms may yield different results. ${ }^{36,37}$ Alternatively, given that the EuroQOL-5 Dimensions is the most frequently used instrument and that a Canadian algorithm for the 5-level version has recently been published, ${ }^{38}$ we could have considered estimating Canadian utility norms using this instrument. However, unlike the HUI3 instrument, which is currently administered within the Canadian Community Health Survey, the EuroQOL-5 Dimensions 5-level instrument has yet to be administered to a large representative sample of all Canadians.
Differences in terms of classification systems, scoring algorithms or sociodemographic characteristics of respondents may hinder comparison of our results with those obtained within other jurisdictions. ${ }^{6,7}$

Finally, beyond the reporting of results specific to age, sex, jurisdiction and self-rated health, we did not examine the effect of any other sociodemographic characteristics or of the presence of any comorbidity reported in the Canadian Community Health Survey. Previous work has shown that sociodemographic characteristics and comorbidity status can influence respondents' utility scores. ${ }^{8-10}$ Future work is required to examine the effect of specific sociodemographic characteristics and of the presence of comorbidities on the current Canadian population with regard to their health-related quality of life and to determine whether previously identified effects still apply.

\section{Conclusion}

In this study, we have estimated Canada-wide utility score norms pertinent to the current Canadian population aged 12 years or older. These benchmark values can be used for comparisons of results obtained within a Canadian study or clinical population and the general Canadian population. Given that we conducted several age, sex and jurisdiction stratifications, these norms may favour the planning and creation of future stratified Canadian economic models, as well as their subsequent evaluation by Canadian outcome researchers and decision-makers.

\section{References}

1. Guidelines for the economic evaluation of health technologies: Canada. 3rd ed. Ottawa: Canadian Agency for Drugs and Technologies in Health; 2006.

2. Guidelines for the economic evaluation of health technologies: Canada. 4th ed. Ottawa: Canadian Agency for Drugs and Technologies in Health; 2017.

3. Choix méthodologiques pour l'évaluation économique à la HAS. Saint-Denis (France): Haute Autorité de Santé; 2011.

4. Guide to the methods of technology appraisal 2013. Process and methods [PMG9]. London (UK): National Institute for Health and Care Excellence; 2013.

5. Ferguson BM, Keown PA. An introduction to utility measurement in health care. Infect Control Hosp Epidemiol 1995;16:240-7.

6. Kind P, Hardman G, Macran S. UK population norms for EQ-5D. CHE Discussion Paper 172. York (UK): University of York, Centre for Health Economics; 1999.

7. Luo N, Johnson JA, Shaw JW, et al. Self-reported health status of the general adult U.S. population as assessed by the EQ-5D and Health Utilities Index. Med Care 2005;43:1078-86.

8. Mittmann N, Trakas K, Risebrough N, et al. Utility scores for chronic conditions in a community-dwelling population. Pharmacoeconomics 1999;15:369-76.

9. Mo F, Choi BC, Li FC, et al. Using Health Utility Index (HUI) for measuring the impact on health-related quality of life (HRQL) among individuals with chronic diseases. ScientificWorld Journal 2004;4:746-57.

10. Schultz SE, Kopec JA. Impact of chronic conditions. Health Rep 2003;14(4):41-53.

11. Steensma C, Loukine L, Orpana H, et al. Describing the population health burden of depression: health-adjusted life expectancy by depression status in Canada. Health Promot Chronic Dis Prev Can 2016;36:205-13.

12. Pohar SL, Jones CA. The burden of Parkinson disease (PD) and concomitant comorbidities. Arch Gerontol Geriatr 2009;49:317-21.

13. Feeny D, Kaplan MS, Huguet N, et al. Comparing population health in the United States and Canada. Popul Health Metr 2010;8:8.

14. Furlong W, Rae C, Feeny D, et al. Health-related quality of life among children with acute lymphoblastic leukemia. Pediatr Blood Cancer 2012;59:717-24.

15. Sanmartin C, Ng E, Blackwell D, et al. Joint Canada/United States survey of health, 2002-03. Cat. No. 82M0022XIE. Ottawa: Statistics Canada; 2004.

16. Fryback DG, Dunham NC, Palta M, et al. US norms for six generic health-related quality-of-life indexes from the National Health Measurement study. Med Care 2007;45:1162-70. 
17. McCallum J, Shadbolt B, Wang D. Self-rated health and survival: a 7-year follow-up study of Australian elderly. Am J Public Health 1994;84:1100-5.

18. Canadian Community Health Survey - annual component (CCHS). Detailed information for 2014. Ottawa: Statistics Canada; 2015 [updated 2015 Apr. 20].

19. Canadian Community Health Survey (CCHS) annual component. User guide 2014 and 2013-2014 microdata files. Ottawa: Statistics Canada; 2015

20. Feeny D. The Health Utilities Index: a tool for assessing health benefits. In: Patient Reported Outcomes Newsletter No. 34, spring issue. Lyon (France): Mapi Research Trust; 2005:2-6.

21. Feeny D, Furlong W, Torrance GW, et al. Multiattribute and single-attribute utility functions for the Health Utilities Index Mark 3 system. Med Care 2002;40:113-28.

22. Horsman J, Furlong W, Feeny D, et al. The Health Utilities Index (HUI): concepts, measurement properties and applications. Health Qual Life Outcomes 2003;1:54.

23. Drummond M. Introducing economic and quality of life measurements into clinical studies. Ann Med 2001;33:344-9.

24. Kaplan MS, Berthelot JM, Feeny D, et al. The predictive validity of healthrelated quality of life measures: mortality in a longitudinal population-based study. Qual Life Res 2007;16:1539-46.

25. Canadian Community Health Survey (CCHS). Annual component - 2014 questionnaire. Ottawa: Statistics Canada; 2014. Available: http://www23.statcan. gc.ca/imdb-bmdi/instrument/3226_Q1_V11-eng.pdf (accessed 2017 Feb. 2).

26. Canadian Community Health Survey (CCHS). Annual component - 2013 questionnaire. Ottawa: Statistics Canada; 2014.

27. Piérard $\mathrm{E}$. The effect of health care expenditures on self-rated health status and the Health Utility Index: evidence from Canada. Int J Health Econ Manag 2016;16:1-21.
28. National Population Health Survey overview, 1994-95. Ottawa: Statistics Canada; 1995.

29. Woo G, Tomlinson G, Yim C, et al. Health state utilities and quality of life in patients with hepatitis B. Can J Gastroenterol 2012;26:445-51.

30. Kopec JA, Schultz SE, Goel V, et al. Can the Health Utilities Index measure change? Med Care 2001;39:562-74.

31. Tarride JE, Burke N, Bischof M, et al. A review of health utilities across conditions common in paediatric and adult populations. Health Qual Life Outcomes 2010;8:12.

32. Brauer CA, Rosen AB, Greenberg D, et al. Trends in the measurement of health utilities in published cost-utility analyses. Value Health 2006;9:213-8.

33. Wisløff T, Hagen G, Hamidi V, et al. Estimating QALY gains in applied studies: a review of cost-utility analyses published in 2010. Pharmacoeconomics 2014; 32:367-75.

34. Brooks R. EuroQol: the current state of play. Health Policy 1996;37:53-72.

35. SF-6D. Sheffield (UK): University of Sheffield; 2017. Available: https://www. shef.ac.uk/scharr/sections/heds/mvh/sf-6d (accessed 2017 Feb. 2).

36. Brazier J. Valuing health states for use in cost-effectiveness analysis. Pharmacoeconomics 2008;26:769-79.

37. Fang M, Oremus M, Tarride JE, et al.; Canadian Willingness-to-Pay Study Group. A comparison of health utility scores calculated using United Kingdom and Canadian preference weights in persons with Alzheimer's disease and their caregivers. Health Qual Life Outcomes 2016;14:105.

38. Xie F, Pullenayegum E, Gaebel K, et al.; Canadian EQ-5D-5L Valuation Study Group. A time trade-off derived value set of the EQ-5D-5L for Canada. Med Care 2016;54:98-105.
Competing interests: David Feeny has a proprietary interest in Health Utilities Incorporated, the firm that distributes the copyrighted Health Utilities Index questionnaires, algorithms and related materials. No other competing interests were declared.

This article has been peer reviewed.

Affiliations: Department of Social and Preventive Medicine (Guertin), Faculty of Medicine, Université Laval; Centre de recherche du CHU de Québec - Université Laval (Guertin), Axe Santé des Populations et Pratiques Optimales en Santé, Hôpital du Saint-Sacrement, Québec, Que.; Department of Economics, Faculty of Social Sciences (Feeny), Centre for Health Economics and Policy Analysis (Feeny, Tarride) and Department of Health Research Methods, Faculty of Health Sciences (Tarride), McMaster University, Hamilton, Ont.; Health Utilities Incorporated (Feeny), Dundas, Ont.; Programs for Assessment of Technology in Health (Tarride), Research Institute of St. Joe's Hamilton, St. Joseph's Healthcare Hamilton, Hamilton, Ont.

Contributors: All of the authors contributed substantively to the work reported in this manuscript, including conception and design of the project. Jason Guertin conducted all of analyses and drafted the first version of the manuscript. David Feeny and Jean-Eric Tarride both contributed to interpretation of results and revised the manuscript for important intellectual content. All of the authors provided approval for the version to be published and agreed to be accountable for all aspects of the work.

Funding: No external funding was received for this study.

Accepted: Aug. 29, 2017

Correspondence to: Jason Guertin, jason. guertin@fmed.ulaval.ca 